\title{
Facebook and Academic Performance: A Positive Outcome
}

\author{
Maria Reyes González, Jose Gasco and Juan Llopis \\ Faculty of Economics, University of Alicante, Spain
}

\begin{abstract}
KEYWORDS Cyber Learning. Issues in Social Networks. Literature Review. Paper Provenance. Research Methodologies
\end{abstract}
ABSTRACT The objective sought with the present paper consists in analyzing the literature about Facebook in order to know the conclusions of the different works with regard to its influence on those results. The examination of 37 papers devoted to this thematic area allows us to know which journals publish more about the impacts that Facebook has on academic performance, which data collection methods are more often used, which topics emerge in parallel to the use of Facebook in the academic context, and which countries are more prolific in this field. The conclusions suggest that, despite the divergence of results, the overall outcome is positive when it comes to the use of Facebook in academic environments.

\section{INTRODUCTION}

Facebook can be a tool not only to relax, since social networks usually constitute an activity associated with spare time and low stress levels, but also to give the student or the teacher the possibility to use it for learning or teaching purposes. Combining Facebook with the usual teaching makes it possible to break the four classroom walls and to provide students with a place where they can interact so that their learning will be effectively improved. However, students or academics may have to face a work overload with Facebook, it is difficult for them to distinguish the useful information from the useless one and Facebook incorporates too many distractions (advertisements, games, etc.), which could harm academic results.

Seeing the contradictory results in relation to the positive or negative effects which can derive from using Facebook in the academic context, the aim of the present paper is to examine the literature about Facebook in order to know the conclusions drawn by the different works with regard to its influence on academic performance. It is an important unexpected outcome of using certain technologies like social networking websites, video games, online auctions or mobile phones that provide user brains with strong rewards and can deteriorate the wellbeing, job and school performance, normal functioning, and health of technology users (Serenko and Turel 2015). The purpose is not only to verify whether students obtain higher grades or teachers are more productive or achieve better performance levels amongst their students, but also, more broadly speaking, if Facebook can create an im- proved work environment in the field of teaching. Although some research has shown a negative relation between Facebook use and academic performance, Junco (2015) suggests that this relation is likely mitigated by multitasking. The analysis of the literature will make it possible to know which journals publish more extensively about this theme, which data collection methods are more often used, which topics emerge in parallel to the utilization of Facebook in academic environments, and which countries are more prolific in this thematic area.

\section{METHODOLOGY}

The present paper will focus on the study of papers published in prestigious and renowned journals; hence the researchers' decision to leave aside other important publication sources such as books or papers presented at conferences. Previous literature review's studies have taken similar decisions (Gonzalez et al. 2013).

Seeking to determine which papers were going to be examined, the researchers' choice was to focus on those published in journals of recognized prestige that dealt with the relationship between Facebook and academic performance. A number of searches in the Proquest database started to be performed for that purpose. The search firstly focused on those papers which contained the terms teaching or learning and Facebook and performance, which left us with 19 papers. The search subsequently continued with academic achievement and Facebook, thus providing another 4 papers. Looking for Facebook and academic performance allowed us to obtain 24 results and, finally, the search for $a c a-$ 
demic results and Facebook gave us 67 more papers. 32 of these 114 papers were repeated; in other words, they had already been found through different searches. A subsequent indepth reading allowed us to identify 36 papers which, despite containing the aforementioned terms in their text, did not deal with the topic of Facebook in academic environments. In order to do this 9 papers published in journals not listed on the Scopus database were removed, thus ensuring scientific rigor in our selection of publications (Bar-Ilan 2008). At the end of this process, there were 37 papers -with January 2015 as the researchers' final search date- dedicated to the topic of Facebook and its impact on academic performance.

\section{RESULTS}

\section{Period Covered and Journals Analyzed}

The researchers' search for papers began without limiting their date of publication, only the final date (since that search finished in Janu- ary 2015), which is why the papers cover from 2010 to 2014. The most outstanding aspect is the upward trend in the number of papers (Table 1), which may be a symptom of the fact that either Facebook is increasingly used in teaching or that the students and the teachers themselves use it to a greater extent nowadays.

Table 1: Year of publication

\begin{tabular}{lccccr}
\hline Year & 2010 & 2011 & 2012 & 2013 & 2014 \\
\hline Papers & 1 & 5 & 7 & 11 & 13 \\
\hline
\end{tabular}

Table 2 additionally lists the journals in which the papers analyzed were published, in turn placing the different journals within a variety of study areas. Many papers have been published in journals which combine the area of Technology with Psychology (with 11 papers), but it is undoubtedly in Education journals that the most papers have been published (18 in all), either in journals about Education as a whole or in others dealing not only with Education but also with other ar-

Table 2: Papers, journals and areas

\begin{tabular}{|c|c|c|c|c|c|c|c|}
\hline Journal & & Papers & Scopus & $J C R$ & Area & & Papers \\
\hline Computers in Human Behavior & 7 & $(18.9 \%)$ & * & * & Technology/ & 11 & $(29.7 \%)$ \\
\hline $\begin{array}{l}\text { Cyberpsycology, Behavior and Social } \\
\text { Networking }\end{array}$ & 2 & $(5.4 \%)$ & * & * & Psychology & & \\
\hline Intal. Journal of Human Computer Studies & 1 & $(2.7 \%)$ & * & * & & & \\
\hline Journal of Cybertherapy and Rehabilitation & 1 & $(2.7 \%)$ & * & - & & & \\
\hline Computers and Education & 4 & $(10.8 \%)$ & * & * & Education/Technology & 7 & $(18.9 \%)$ \\
\hline British Journal of Educational Technology & 1 & $(2.7 \%)$ & * & * & & & \\
\hline Journal of Computer Assisted Learning & 1 & $(2.7 \%)$ & * & * & & & \\
\hline Learning, Media and Technology & 1 & $(2.7 \%)$ & * & * & & & \\
\hline $\begin{array}{l}\text { TOJET: The Turkish Online Journal of } \\
\text { Educational Technology }\end{array}$ & 3 & $(8.1 \%)$ & * & - & Education & 6 & $(16.2 \%)$ \\
\hline Education for Information & 1 & $(2.7 \%)$ & * & - & & & \\
\hline $\begin{array}{l}\text { RUSC. Universities and Knowledge } \\
\text { Society Journal }\end{array}$ & 1 & $(2.7 \%)$ & * & - & & & \\
\hline American Journal of Distance Education & 1 & $(2.7 \%)$ & * & - & & & \\
\hline Anatomical Sciences Education & 1 & $(2.7 \%)$ & * & - & Education/Health & 5 & $(13.5 \%)$ \\
\hline $\begin{array}{l}\text { Electronic Journal of Research in } \\
\text { Educational Psychology }\end{array}$ & 1 & $(2.7 \%)$ & * & - & & & \\
\hline Medical Education Online & 1 & $(2.7 \%)$ & * & * & & & \\
\hline Nurse Education in Practice & 1 & $(2.7 \%)$ & * & - & & & \\
\hline Nurse Education Today & 1 & $(2.7 \%)$ & * & * & & & \\
\hline Asian Social Science & 3 & $(8.1 \%)$ & * & - & Social Sciences & 3 & $(8.1 \%)$ \\
\hline Journal of Black Studies & 1 & $(2.7 \%)$ & * & * & Anthropology & 2 & $(5.4 \%)$ \\
\hline Anthropologist & 1 & $(2.7 \%)$ & * & * & & & \\
\hline TechTrends & 1 & $(2.7 \%)$ & * & - & Technology & 1 & $(2.7 \%)$ \\
\hline $\begin{array}{l}\text { 3L: The Southeast Asian Journal for English } \\
\text { Language Studies }\end{array}$ & 1 & $(2.7 \%)$ & * & - & Linguistics & 1 & $(2.7 \%)$ \\
\hline Media International Australia & 1 & $(2.7 \%)$ & * & * & Media & 1 & $(2.7 \%)$ \\
\hline Total & & $00.0 \%)$ & & & & 37( & $(100.0 \%)$ \\
\hline
\end{tabular}


eas such as Technology and Health. Nevertheless, it is likewise worth highlighting the broad interest raised by this topic, which has been dealt with or published in journals of various areas, including the aforementioned ones -Psychology, Technology and Education- along with others such as Social Sciences, Anthropology, Linguistics or Mass Media.

All the papers analyzed were published in journals indexed on Scopus, and also that 12 out of the 23 journals which publish those papers are additionally listed on the JCR index of the Thomson Publishing House, the number of papers analyzed which are collected on the JCR index amounting to 22 (59.4\% of the total).

\section{Methodological Aspects}

Table 3 provides information about the methodological aspects related to the papers examined. The methods utilized explain us the way in which information is collected when preparing a study. All the papers analyzed are empirical. Field studies especially prevail, with more than half of the papers located in that methodology. Amongst them stand out the works of Paul et al. (2012) where a survey is administered to Business Administration students for the purpose of determining whether the time dedicated to social networks such as Facebook impacted negatively on their academic performance, or that of Junco (2012b), which focuses on the extent to which in-class multitasking can influence academic results -especially through the use of social networks. Both studies nicely illustrate a large volume of collected data (340 valid questionnaires in the first case, and 1,939 in the second one) that allow for the generalization of results.

The second most frequent research method amongst the papers examined is case study com- bined with field study. Information is obtained through direct observation in case studies. The paper by Sutcliffe and Alrayes (2012) is representative of these papers, which reflect a combination of the aforesaid two methods.

In third place, there are only four case studies. For instance, the study carried out by Goodband et al. (2012) deals with the use of Facebook applied to the learning of mathematics. The authors of this work use the literal citations of participants in the case for its description, the numerical contribution about the case under examination being scarce.

There are two studies which, the same as the present one, have a literature review as their basis. The paper by Hew (2011) focuses on the literature devoted to the utilization of Facebook by students and teachers through the analysis of 36 papers. This study examines the profile of Facebook users, the effects of Facebook and finally, the attitudes towards Facebook. Finally, the paper by Cahn et al. (2013) is based on the analysis of web pages existing in different medical schools for the purpose of examining the information that they provide about social networks which give specialized information to medical professionals.

Table 3 additionally supplies information about the use of statistical methods for information analysis purposes. The sum of percentages in this section exceeds 100, insofar as the same paper may use one or more statistical techniques (the average number of techniques used in the papers examined is 1.8).

Most of the studies utilize some statistical technique or another, amongst which stands out merely descriptive statistics, together with other more elaborate techniques, such as: study of reliability and validity of the variables used; means difference test; factor analysis; Anova or Mano-

Table 3: Methods

\begin{tabular}{|c|c|c|c|c|}
\hline Research Methods & Empirical & $37(100 \%)$ & $\begin{array}{l}\text { Field Study } \\
\text { Case/Field Study } \\
\text { Case } \\
\text { Literature Review } \\
\text { WEB Analysis }\end{array}$ & $\begin{array}{rr}23 & (62.1 \%) \\
7 & (18.9 \%) \\
4 & (10.8 \%) \\
2 & (5.4 \%) \\
1 & (2.7 \%)\end{array}$ \\
\hline Statistical Techniques & $\begin{array}{l}\text { No } \\
\text { Yes }\end{array}$ & $\begin{aligned} 4 & (10.8 \%) \\
33 & (89.2 \%)\end{aligned}$ & $\begin{array}{l}\text { Descriptive } \\
\text { Reliability / Validity } \\
\text { Means Difference } \\
\text { Factor analysis } \\
\text { ANOVA/MANOVA } \\
\text { Regression } \\
\text { Structural Equation }\end{array}$ & $\begin{array}{rr}20 & (54.0 \%) \\
8 & (21.6 \%) \\
3 & (8.1 \%) \\
2 & (5.4 \%) \\
3 & (8.1 \%) \\
8 & (21.6 \%) \\
3 & (8.1 \%)\end{array}$ \\
\hline
\end{tabular}


va test; regression analysis; or the use of structural equations. Despite the widespread utilization of statistical techniques for the elaboration of information, highly sophisticated techniques (such as structural equations or regression analyses) are rarely used. The models for Facebook study in teaching improvement are still quite simple, not often going beyond a merely descriptive analysis.

\section{Thematic Aspects}

\section{Technologies, Application Areas, and Study Object}

Nearly half of the papers analyzed (18, that is, $48.6 \%$ ) do not study the use of Facebook alone but in combination with other technologies such as, above all, Twitter (7 works), Youtube or videos (6 works), wiki (3 works), Blogs (3 works), virtual worlds (2 works), as well as plenty of other technologies which were mentioned in only one paper, including e-mail, e-portfolio, ethnic SNS, Moodle, Blackboard, Flickr, QR codes, or Postcast (see Table 4). Facebook thus fulfils a number of functions in teaching which are likely to be supplemented and complemented by other technologies; for this reason, the sum of percentages in this section exceeds 100 percent.

This same Table 4 shows us the specific fields of education on which the papers analyzed are based. Even though almost half of the papers examined (16, 43.2\%) do not specify the study area where Facebook is being applied, many more papers $(20,54.1 \%)$ do identify the areas in which its application is being monitored. The most commonly studied area is Health, followed by Business Administration, but there are also studies pertaining to the areas of Language, Education, Mathematics, Statistics, Computing or Information Sciences. This reveals us the wide range of teaching contexts where the utilization of Facebook as a teaching tool has been experimented and documented.

Although teachers may use Facebook as a teaching -or, more broadly speaking, academictool, a majority of studies pay attention to the utilization of Facebook by students, or students and the teacher, and only three of them examine the influence of Facebook on teachers.

\section{Topics Analyzed}

All the papers examined share one topic of interest, namely: the influence exerted by Facebook - the social networking site par excellenceon the academic results, either of students or of teachers. Nevertheless, many other topics arise next to this one -as seem in Table 5 . In order to obtain such topics the researchers' read the whole text, especially the results and conclusions, so that the topics acquiring the greatest relevance could be identified. The resulting topics or categories were neither mutually exclusive nor collectively exhaustive; one paper may fall upon several thematic areas, and more topics actually emerged as progress was made in the reading. Previous studies (Gonzalez et al. 2006) have adopted a similar reasoning when it comes to classifying papers by topics: not limiting or

Table 4: Technologies, application areas and study object

\begin{tabular}{|c|c|c|c|c|}
\hline \multirow[t]{7}{*}{ Technologies } & Facebook & \multirow{6}{*}{$18(48.6 \%)$} & & \multirow[b]{2}{*}{$7(18.9 \%$} \\
\hline & \multirow[t]{5}{*}{ Facebook and others } & & Twitter & \\
\hline & & & Youtube/videos & $6(16.2 \%$ \\
\hline & & & Wiki & $3(8.1 \%$ \\
\hline & & & Blogs & $3 \quad(8.1 \%$ \\
\hline & & & Others & $11(29.7 \%$ \\
\hline & Object & & & Area \\
\hline Student & $31(83.7 \%)$ & & Non-specified & $16(43.2 \%$ \\
\hline Teacher & $3(8.1 \%)$ & & Health & $7(18.9 \%$ \\
\hline \multirow{7}{*}{ Both } & $3 \quad(8.1 \%)$ & & Business & $4(10.8 \%$ \\
\hline & & & Languages & $3(8.1 \%$ \\
\hline & & & Education & $(5.4 \%$ \\
\hline & & & Math/Statistics & $(5.4 \%$ \\
\hline & & & Computers & $(2.7 \%$ \\
\hline & & & Business/Education & $1 \quad(2.7 \%$ \\
\hline & & & Information Sciences & $1 \quad(2.7 \%$ \\
\hline
\end{tabular}


forcing categories because of pre-conceived ideas (such as using only keywords, for instance); allowing for the appearance of additional topics when more papers are examined; finishing when saturation takes place, that is, when no different topics arise

Table 5 classifies papers by topics, bearing in mind that the influence which Facebook has as an instrument for academic improvement is a common topic in all of them, and that it does not appear in this table. Although many of the topics suggested appear mixed and even blurred in a large number of papers, those papers which more evidently deal with a specific theme have been counted both in Table 5 .

It can be checked how many papers, up to 22, envisage Facebook as a tool which allows for collaboration, that is, joint work, either between students, or between the latter and their teachers, or only between teachers, which seems logical because it is above all a communication and interaction tool (Gonzalez et al. 2015). For instance, a comparison is drawn between Facebook and Moodle as teaching instruments in the study by Petrovic et al. (2014).

Table 5: Topics

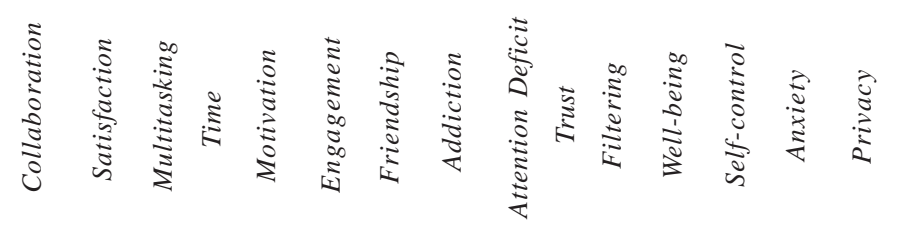

Alloway et al. 2013

Al-Rahmi, Othman and Musa 2014

Arabacioglu and Akar-Vural 2014

Aubry 2013

Baris and Tosun 2013

Cahn, Benjamin and Shanahan 2013

Chang and Lee 2013

Francois, Hebbani and Rintel 2013

George et al. 2013

Goodband et al. 2012

Hew 2011

Huang and Hung 2013

Jaffar 2014

Judd 2014

Junco 2012a

Junco 2012b

Kalpidou, Costin and Morris 2011

Kaur, Ganapathy and Sidhu 2012

Kirschner and Karpinski 2010

Kucuk and Sahin 2013

Lateh 2014

Lee 2014

Manca and Ranierit 2013

McAlexander et al. 2011

Morley 2014

Park, Song and Lee 2014

Paul, Baker and Cochran 2012

Petrovic et al. 2014

Román and Martín 2014

Rouis 2012

Rouis, Limayem and Salehi-Sangari 2011

Sarrafzadeh, Hazeri and Alavi 2011

Sutcliffe and Alrayes 2012

Tower, Latimer and Hewitt 2014

Wohn and LaRose 2014

Yuksel 2013

Zaremohzzabieh et al. 2014

Papers

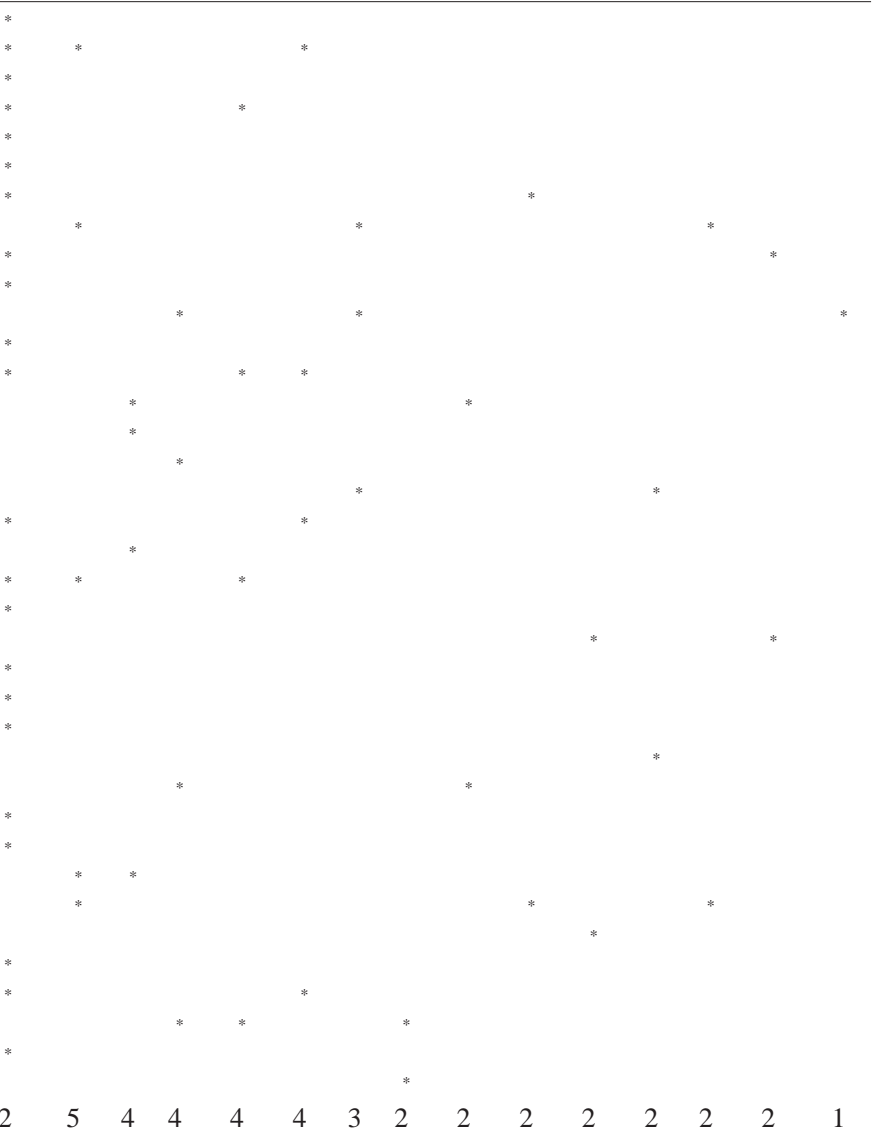


A total of 5 papers relate the utilization of Facebook as a teaching instrument to the degree of satisfaction achieved thanks to this experience. For example Rouis et al. (2011) established as hypothesis that using Facebook increases the level of satisfaction with life because it represents a modern form of activity typically associated with leisure and because it is a communication tool that students often use to keep in touch with their friends and relatives. Similarly in Brazil, Oliviera and Huertas (2015) find out that Life Satisfaction influence on We-Intention is mediated by Subjective Norm, Group Norm, Social Identity, Entertainment Value, and Maintaining Interpersonal Interconnectivity including Facebook.

Another of the issues which emerge is multitasking. This topic receives a specific treatment in 4 works. For example, Judd (2014) points out that regardless of whether Facebook might be a cause of multitasking or only one of its symptoms, both the use of Facebook use and the high multitasking levels associated with it are likely to generate the capacity to reduce the effectiveness of a student's self-directed study.

\section{DISCUSSION}

It cannot be denied that the utilization of $\mathrm{Fa}-$ cebook is time-consuming and that this may go to the detriment of academic results. Also 4 works have dealt with this issue. The study by Paul et al. (2012) therefore analyzes both the time that students spend on Facebook and the time management, the self-regulation applied by the actual student on Facebook.

Another connection studied by 4 of the papers analyzed is the one existing between Facebook and Motivation. This relationship is positive in the studies examined, as it happens in the paper by Aubry (2013), who describes the use of Facebook in a group created to learn French. The conclusions of this study were that a significant number of Facebook users might have gone from having only an extrinsic motivation for their study to developing an intrinsic one as well.

The topic of engagement is present in another 4 papers. Engagement could be understood as the amount of physical and mental energy that a student dedicates to the academic experience. In this regard, a number of works reach the conclusion that using Facebook as a teaching instrument may increase the degree of engage- ment with studying; thus, the work of Jaffar (2014) stresses that Facebook must be used as an educational resource, not only because in fact students are already using it but also for its potential to stimulate learning.

Results by Maier et al. (2015) show that SNS (Social Network Services) -stress creators and SNS-exhaustion cause discontinuous usage intentions, and switching-stress creators and switching-exhaustion reduce these intentions.

Some papers -more precisely 3 of them-deal with the topic of friendship, for example, the number of Facebook friends. In this respect, the conclusion derived from the research carried out by Kalpidou et al. (2011) is that it would be necessary to carry out a more in-depth study about the notion of friendship on Facebook. This same paper highlights that, in the case of students enrolled in the first years, the more friends they have on Facebook the worse they usually adapt to academic life. However, amongst students of the last years, the number of Facebook friends positively correlates with their attachment to the educational institution.

Without a doubt, Facebook may become addictive, and a lot of students or teachers eventually develop a compulsive use of it. This topic is treated in 3 works. The main axis for the paper by Zaremohzzabierh et al. (2014) is precisely to explore the addiction to Facebook amongst students. According to this paper, the addiction is reflected on the compulsive checking of Facebook, the high frequency of its use, and the utilization of this social network as a way to avoid other 'offline' responsibilities.

Facebook provides plenty of distractions which are likely to cause or worsen attention at work or when studying. This issue of attention deficit constitutes the focus of interest in two papers; one of them is the study by Paul et al. (2012). It claims that a high attention deficit is associated with a larger amount of time allocated to the use of social networks.

The topic of trust is examined in 2 works, one of them by Chang and Lee (2013) where it is stated that trust between students increases mutual collaboration, and also that participants who have a high level of trust with their partners will be able to learn more from them than those with lower trust levels.

Before the possible negative effects caused by Facebook, quite a few studies highlight that there may be or there is censorship. The work of 
Lee (2014) which analyzes the utilization of Facebook amongst teenagers, stresses the need for a parental control which can limit both the use and the negative impact of Facebook on academic performance.

Two of the papers analyzed deal with Facebook and its relationship with students' wellbeing. Park et al. (2014) showed that the Asian students who study in the United States and use Facebook have a higher level of psychological well-being than those who do not use any type of social network or those who utilize ethnic social networks (that is, more typical of their language or their country).Facebook use requires a certain degree of self-regulation or self-control, as is especially highlighted by two works. Rouis et al. (2011) argue that students with a self-regulation capacity can limit the amount of time that they invest in Facebook and, therefore, its use will not impact negatively on their academic performance. Furthermore, 2 papers focus on the connection between Facebook and anxiety. George et al. (2013) tell an experience in the use of Facebook groups to handle and reduce the stress typically associated with the first years of medical students.

Finally, the paper by Hew (2011) highlights the topic of privacy on Facebook. His review of the literature about this topic provides contradictory results with students who are not concerned about the issue of privacy and others who are reluctant to use Facebook due to privacy problems or because they wish to keep their profile as private.

The present work deals with Facebook and its influence on academic results or on the teaching context, which is why one of the most important outcomes of our analysis is that almost half of the papers dedicated to the influence exerted by Facebook on teaching (16 papers; 43\%) do not obtain a clear conclusion about whether Facebook affects academic performance positively or negatively. However, amongst those which do obtain a conclusion, a vast majority (15 papers; 41\%) share the idea that Facebook has a positive influence on academic results, and only $6(16 \%)$ convey a clearly negative opinion about the way in which Facebook affects performance or the academic environment.

Even though there is an evident numerical supremacy of papers coming from the United States due to the prevalence of this country in most academic areas, Table 6 reflects the great interest raised by this topic amongst researchers from all over the world. Table 6 was elaborated taking as a reference the provenance of the authors who appear at the work, understanding as such the universities where they develop their teaching and research activity.

Table 6: Paper provenance

\begin{tabular}{lr}
\hline Country & No. \\
\hline USA & 11 \\
Turkey & 4 \\
Australia, UK, Malaysia & 3 \\
Taiwan, Sweden & 2 \\
Arab Emirates, Spain, Iran, Italy, & 1 \\
$\quad$ Korea, the Netherlands, Serbia, & \\
Singapore, Thailand & 1 \\
\hline
\end{tabular}

The literature about the impact of Facebook on academic performance and about its potential as a tool to improve the teaching context is quite recent. In fact, the first papers about this topic were published in 2010. This type of work has been published in academic journals belonging to different fields: Education, Psychology, Anthropology, Linguistics and Mass Media.

\section{CONCLUSION}

Although the topic which brings together all the papers examined is the impact of Facebook on academic results and/or its potential to improve the academic work environment, other topics of great interest emerge in the papers under study. Some of these topics are positive towards the utilization of Facebook as a teaching instrument; for instance, a majority of studies highlight the advantages of Facebook as a space for collaboration, joint work and interaction. Another positive effect would be the improved satisfaction levels that the users of this technology can reach, the increased motivation on the part of students which results from working with a well-known and user-friendly tool, the engagement or dedication focused on studying that is likely to grow thanks to the use of Facebook, and the possibility to make friends or maintain friendships which contribute to improve the study or work environment. However, negative aspects arise too, such as the proneness to multitasking which results in distractions and lack of focus on the subject matter, the time which Facebook can take away from the purely academic tasks, the addiction that it is likely to cre- 
ate and its drawbacks when it comes to security or concentration, as well as the consequent attention deficit that many students suffer from.

The fact that these results are contradictory makes it necessary to carry out an overall assessment. An attempt was made to classify the papers under study into three groups depending on whether they are conclusive with regard to the positive effects caused by Facebook on the academic environment or, on the contrary, they transmit a negative opinion or their conclusions are ambiguous or not sufficiently well-defined. In our view, this is the most important contribution made by the present study and, although almost half of the papers analyzed are ambiguous about this issue, amongst those which do obtain a conclusion, most of them state that Facebook impacts positively on academic performance.

As for the limitations, it must be taken into account that our findings are based on the 37 papers about the effects of Facebook on the academic context-no books or other types of publications which perhaps could have given rise to other results were examined. Nevertheless, the present paper contains useful contributions both from the research and from the teaching point of view. From the former, because it helps us delve deeper into a topic of interest for any researcher on the field of teaching; and for teachers, because they can analyze and study other colleagues' experiences with the aim of carrying out their own attempts of immersion into this social network.

\section{REFERENCES}

Alloway TP, Horton J, Alloway RG, Dawson C 2013. Social networking sites and cognitive abilities: Do they make you smarter? Computers and Education, 63: $10-16$.

Al-Rahmi WM, Othman MS, Musa MA 2014. The improvement of students' academic performance by using social media through collaborative learning in Malaysian higher education. Asian Social Science, 10: 210-221.

Arabacioglu T, Akar-Vural R 2014. Using Facebook as a LMS? TOJET: The Turkish Online Journal of Educational Technology, 13: 202-215.

Aubry J 2013. Facebook-induced motivation shifts in a French online course. TechTrends, 57: 81-87.

Bar-Ilan J 2008. Which h-index? - A comparison of WoS, Scopus and Google Scholar. Scientometrics, 74: 257-271.

Baris MF, Tosun N 2013. Can social networks and Eportfolio be used together for enhancing learning effects and attitudes? TOJET: The Turkish Online Journal of Educational Technology, 12: 51-62.

Cahn PS, Benjamin EJ, Shanaha CW 2013. 'Uncrunching' time: Medical schools' use of social media for faculty development. Medical Education Online, 18: 1-6.

Chang W-L, Lee C-Y 2013. Trust as a learning facilitator that affects students' learning performance in the Facebook community: An investigation in a Business Planning Writing Course. Computers and Education, 62: 320-327.

Francois A, Hebbani, Rintel S 2013. Facebook in the university workplace. Media International Australia, 149: 15-27.

George DR, Dellasega C, Whitehead MM, Bordon A 2013. Facebook-based stress management resources for first-year medical students: A multi-method evaluation. Computers in Human Behavior, 29: 559562.

Gonzalez R, Gasco J, Llopis J 2006. Information systems outsourcing: A literature analysis. Information and Management, 43: 821-834.

Gonzalez R, Llopis J, Gasco J 2013. Information systems offshore outsourcing: Managerial conclusions from academic research. International Entrepreneurship and Management Journal, 9: 229-259.

Gonzalez R, Gasco J, Llopis J 2015. Facebook in teaching: Strengths and weaknesses. International Journal of Information and Learning Technology, 32: 6578.

Goodband JH, Solomon Y, Samuels PC, Lawson D, Bhakta R 2012. Limits and potentials of social networking in academia: Case study of the evolution of a mathematics Facebook community. Learning, Media and Technology, 37: 236-252.

Hew KF 2011. Students' and teachers' use of Facebook. Computers in Human Behavior, 27: 662676.

Huang H-T, Hung S-T 2013. Exploring the utility of a video-based online EFL discussion forum. British Journal of Educational Technology, 44: E-90-E94.

Jaffar AA 2014. Exploring the use of a Facebook page in anatomy education. Anatomical Sciences Education, 7: 199-208.

Judd T 2014. Making sense of multitasking: The role of Facebook. Computers and Education, 70: 194-202.

Junco R 2012a. Too much face and not enough books: The relationship between multiple indices of Facebook use and academic performance. Computers in Human Behavior, 28: 187-198.

Junco R 2012b. In-class multitasking and academic performance. Computers in Human Behavior, 28: 2236-2243.

Junco R 2015. Student class standing, Facebook use, and academic performance. Journal of Applied Developmental Psychology, 36: 18-29.

Kalpidou M, Costin D Morris J 2011. The relationship between Facebook and the well-being of undergraduate college students. Cyberpsychology, Behavior, and Social Networking, 14: 183-189.

Kaur S, Ganapathy M, Sidhu GK 2012. Designing learning elements using the multiliteracies approach in an ESL writing classroom. The Southeast Asian Journal of English Language Studies, 18: 119-134.

Kirschner PA, Karpinski AC 2010. Facebook and academic performance. Computers in Human Behavior, 26: $1237-1245$. 
Kucuk S, Sahin I 2013. From the perspective of community of inquiry framework: An examination of Facebook uses by pre-service teachers as a learning environment. TOJET: The Turkish Online Journal of Educational Technology, 12: 142-156.

Lateh A 2014. Integrating Facebook social network for the statistics course: Its outcomes of undergraduate students' Prince of Songkla University Pattani Campus. Asian Social Science, 10: 212-219.

Lee EB 2014. Facebook use and texting among African American and Hispanic teenagers: An implication for academic performance. Journal of Black Studies, 45: 83-101.

Manca S, Ranieri M 2013. Is it a tool suitable for learning? A critical review of the literature on Facebook as a technology-enhanced learning environment. Journal of Computer Assisted Learning, 29: 487-504.

Maier C, Laumer S, Weinert C, Weitzer T 2015. The effects of technostress and switching stress on discontinued use of social networking services: A study of Facebook use. Informations Systems Journal, 25(3): 275-308.

McAlexander KM, Sahnoune I, Alastuey L, Bode S, Lee $\mathrm{R}$ 2011. Using virtual and real, immersive technologies to enhance learning in obesity studies. Journal of Cybertherapy and Rehabilitation, 4: 455-460.

Morley DA 2014. Supporting student nurses in practice with additional online communication tools. Nurse Education in Practice, 14: 69-75.

Oliviera MJ, Huertas MKZ 2015. Does Life Satisfaction influence the intention (We-Intention) to use Facebook? Computers in Human Behaviour, 50: 205-210.

Park N, Song H, Lee KM 2014. Social networking sites and other media use, acculturation stress, and psychological well-being among East Asian college students in the United States. Computers in Human Behavior, 36: 138-146.

Paul JA, Baker HM, Cochran JD 2012. Effect of online social networking on student academic performance. Computers in Human Behavior, 28: 2117-2127.
Petrovic N, Jeremic V, Cirovic M, Radojicic Z, Milenkovic N 2014. Facebook versus Moodle in practice. The American Journal of Distance Education, 28: 117-125.

Román P, Martín A 2014. Social networks as tools for acquiring competences at university: QR codes through Facebook. RUSC, 11: 27-41.

Rouis S 2012. Impact of cognitive absorption on Facebook on students' achievement. Cyberpsychology, Behavior, and Social Networking, 15: 296-303.

Rouis S, Limayem M, Salehi-Sangari E 2011. Impact of Facebook usage on students' academic achievement: Role of self-regulation and trust. Electronic Journal of Research in Educational Psychology, 9: 961-994.

Sarrafzadeh M, Hazeri A, Alavi S 2011. The status of Web 2.0 in Iran's LIS education. Education for Information, 28: 233-245.

Serenko A, Turel O 2015. Integrating technology addiction and use: An empirical investigation of Facebook users. Integrating Technology Addition and Use, 1(2): 1-18

Sutcliffe A, Alrayes A 2012. Investigating user experience in Second Life for collaborative learning. International Journal of Human-Computer Studies, 70: 508-525.

Tower M, Latimer S, Hewitt J 2014. Social networking as a learning tool: Nursing students' perception of efficacy. Nurse Education Today, 34: 1012-1017.

Wohn DY, LaRose R 2014. Effects of loneliness and differential usage of Facebook on college adjustment of first-year students. Computers and Education, 76: 158-167.

Yuksel D 2013. Technology use in reflective teaching: A practicum research project. Anthropologist, 16: 145-152.

Zaremohzzabieh Z, Samah BA, Omar SZ, Bolong J, Kamarudin NA 2014. Addictive Facebook use among university students. Asian Social Science, 10: 107116. 